\title{
A Seamless Gene Deletion Method and Its Application for Regulation of Higher Alcohols and Ester in Baijiu Saccharomyces cerevisiae
}

\author{
Ping Li, ${ }^{1}$ Junling Ge, ${ }^{1}$ Yingying Gao, ${ }^{1}$ Jianhui Wang, \\ Cuiying Zhang $\mathbb{D}^{1,2}$ and Dongguang Xiao ${ }^{1}$ \\ ${ }^{1}$ State Key Laboratory of Food Nutrition and Safety, Key Laboratory of Industrial Fermentation Microbiology, \\ Ministry of Education, Tianjin Industrial Microbiology Key Laboratory, College of Biotechnology, Tianjin University of \\ Science and Technology, Tianjin 300457, China \\ ${ }^{2}$ Key Laboratory of Wuliangye-flavor Liquor Solid-state Fermentation, China National Light Industry, China
}

Correspondence should be addressed to Cuiying Zhang; cyzhangcy@tust.edu.cn

Received 19 January 2019; Accepted 22 April 2019; Published 9 May 2019

Academic Editor: Antonio Teixeira

Copyright (C) 2019 Ping Li et al. This is an open access article distributed under the Creative Commons Attribution License, which permits unrestricted use, distribution, and reproduction in any medium, provided the original work is properly cited.

\begin{abstract}
The security of engineering Saccharomyces cerevisiae is becoming more focused on industrial production in consideration of the public concern regarding genetically modified organisms. In this work, a rapid and highly efficient system for seamless gene deletion in S. cerevisiae was developed through two-step integration protocol combined with endonuclease I-SCEI expression. The factors affecting the frequency of the second homologous recombination were optimized, and studies indicated that the mutant strains with $500 \mathrm{bp}$ direct repeats and that have been incubating in galactose $(0.5 \mathrm{~g} / 100 \mathrm{~mL})$ medium at $30^{\circ} \mathrm{C}$ and $180 \mathrm{r} / \mathrm{min}$ for 24 $\mathrm{h}$ permit high frequency $\left(6.86 \times 10^{-4}\right)$ of the second homologous recombination. Furthermore, DNA sequence assays showed only self-DNA in native location without any foreign genes after deletion using this method. The seamless gene deletion method was applied to the construction of the engineering strains with BAT2 (encoding aminotransferase) deletion and ATF1 (alcohol acetyltransferases) overexpression. The mutants exhibited significant effects on higher alcohol reduction and ester improvement after Baijiu fermentation. The engineered strains can be used in industrial production in security, thereby meeting the requirements of modern science and technology.
\end{abstract}

\section{Introduction}

Saccharomyces cerevisiae is widely used for industrial production as an efficient and important fermentation microorganism because of its advantageous qualities, such as highethanol productivity, tolerance to process hardiness, and tolerance to fermentation byproducts; therefore, it is preferred for crop ethanol production [1-3]. Meanwhile, with the public's increasing concern about genetically modified (GM) organisms, the security of genetically engineered strains has attracted an increasing amount of attention.

Baijiu (Chinese liquor) presents peculiar sensory characteristics and has health-promoting effects. S. cerevisiae is the dominant microorganism in Baijiu fermentation and is closely related to the quality of Baijiu. S. cerevisiae is not only responsible for the efficient production of ethanol, it can also be manipulated to produce other heterologous flavor substances during alcoholic fermentation. Acetate esters and higher alcohols are significant parameters in the determination of the beverage's quality and flavor profiles [4-6]. Higher alcohols can lead to fusel oil taste and cause potential damage to human health at high levels [7]. Acetate esters, such as ethyl acetate, isoamyl acetate, and isobutyl acetate, are among the flavor-active esters that can elicit the desired fruity aroma in alcoholic drinks [8].

Systematic sequencing of $S$. cerevisiae genome has revealed a profusion of Open Reading Frames, and a large majority of genes need to be mediated to determine its phenotypic effects $[9,10]$. To date, several genome editing protocols have been widely employed and developed 
for S. cerevisiae [11-16]. Cre/loxP recombination is used as a site-specific recombinase technology for controlling gene expression; it relies on the integration of 34-bp loxP sequences directly upstream and downstream of the genomic target by one double homologous or two single homologous recombination events. The cassette can precisely be removed with the induction of Cre recombinase and used again for the succeeding deletion step. However, a scar is left in the chromosome in the form of loxP site after each deletion step, thereby affecting the efficiency of the next gene deletion. Recent research has demonstrated that CRISPRassociated (Cas) systems can serve as the basis of a simple and highly efficient method for manipulating the genome in bacteria, yeast, and human cells [17-21]. The CRISPRassociated enzyme Cas9 is an RNA-guided endonuclease that uses RNA:DNA base-pairing to target foreign DNA [22-24]. However, the key limitation of this system is off-target effects. Single guide RNA (SgRNA), which guides the CRISPR/Cas9 to interrogate the genome and matches the targeted DNA fragment, can tolerate certain mismatches to the DNA targets, thereby promoting undesired off-target mutagenesis [25-27]. To solve these problems, an improved and efficient system should be developed for genome editing in $S$. cerevisiae.

Repair of chromosomal double-strand breaks (DSBs) can be accomplished through homologous recombination in their immediate vicinity on the chromosome in a variety of organisms [28, 29]. Galactose-inducible I-SCE1 endonuclease can be used to incorporate an inducible DSB feature [30]. In the current study, we developed a rapid and highly efficient system through two-step integration protocol combined with endonuclease I-SCEI expression to accelerate the pace and efficiency of progress of seamless gene deletion in Baijiu $S$. cerevisiae. Furthermore, the factors affecting the frequency of the second homologous recombination efficiency, including the length of direct repeat (DR) sequences, induction time, and galactose concentration, were screened and optimized. Using the toolkit, the $S$. cerevisiae with BAT2 (encoding aminotransferase) deletion and ATF1 (encoding alcohol acetyltransferases) overexpression were engineered to reduce the higher alcohol concentration and improve the acetate ester production in Baijiu. This study could serve as a good reference for genome editing and future optimization of yeast strains in alcoholic beverages.

\section{Materials and Methods}

2.1. Strains, Culture Conditions, and Media. Strains used in this work are shown in Table 1. Escherichia coli was used to construct plasmids. S. cerevisiae strain $\alpha 5$ was used as the parent strain; this was cultured in yeast extract peptone dextrose (YEPD) (1\% yeast extract, $2 \%$ peptone, and $2 \%$ glucose) for general culturing and in galactose medium (1\% yeast extract, $2 \%$ peptone, $100 \mathrm{mg} / \mathrm{L}$ adenine hemisulfate, and $1 \%$ galactose) for galactose induction. Selection and counter-selection were performed in the medium TPGly + AF (1\% yeast extract, $2 \%$ peptone, $5 \%$ glycerol, $200 \mathrm{mg} / \mathrm{mL}$ methotrexate, $5 \mathrm{mg} / \mathrm{mL}$ sulfanilamide, $5 \mathrm{mg} / \mathrm{mL}$ thymidine, and $50 \mathrm{mg} / \mathrm{mL}$ hypoxanthine) and the medium SC + FUdR $\left[0.17 \% \mathrm{YNB}, 0.5 \%\left(\mathrm{NH}_{4}\right)_{2} \mathrm{SO}_{4}, 2 \%\right.$ glucose, $50 \mu \mathrm{g} / \mathrm{mL} 5-$ fluorodeoxyuridine (FudR)], respectively.

2.2. Plasmid Construction. The primers designed in this study are listed in Table 2. The plasmid pUC19-UD was constructed as follows. pUC19 was used as backbone. Upstream $B A T 2-U(1500)$ and downstream BAT2-D(1500) were amplified from yeast strain $\alpha 5$ with primers BAT2-A(KpnI)F/BAT2-A-R and BAT2-B-F/BAT2-B(SphI)-R, respectively. Fusion polymerase chain reaction (PCR) with a mixture of upstream and downstream sequences was carried out. Then, the PCR product was KpnI-SphI double-digested and inserted in the same KpnI-SphI digested plasmid pUC19, thereby creating the plasmid pUC19-UD.

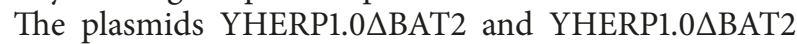
::ATF1 were constructed as follows. First, the HERP1.0 $\left(P_{G A L 1}{ }^{-}\right.$ $\left.I-S C E I-P_{T E F 1}-H S V-T K-T_{T E F 1}\right)$ was amplified using the primers YH1.0(EcoRI)-F/YH1.0(SphI)-R from the yeast yWH245 gifted by William G [30]. The cassette was inserted into EcoRI-SphI-digested plasmid Yep352, creating the plasmid YHERP1.0. Second, the fragment of BAT2-UD (1183 bp) amplified from pUC19-UD with the primers $B+500$ bpF/BAT2-B-R and the fragment $B A-P_{T E F 1}-A T F 1-T_{P G K 1}-B B$ (3600 bp) amplified from pUC-BBTAP preserved in this laboratory by the primers $\mathrm{YH} 1.0 \Delta \mathrm{B}:: \mathrm{A}-\mathrm{F} / \mathrm{YH} 1.0 \Delta \mathrm{B}: \mathrm{A}-\mathrm{R}$ were cloned into the plasmid YHERP1.0 digested with $K p n \mathrm{I}$, obtaining the plasmids YHERP1.0 $\triangle \mathrm{BAT} 2$ (Figure 1) and YHERP1.0DBAT2::ATF1.

2.3. First Step of Integration of HERP1.0 Cassette. Primers BAT2-A-F and BAT2-A-R(F) [containing the restriction site for I-SCEI (S) and $27 \mathrm{bp}$ homologous sequence $(\mathrm{F})$ of the HERP1.0] were used to amplify the fragment BAT2-A(RSF) from the yeast $\alpha 5$ chromosome. Then, the fragment $R S$ HERP1.0-BAT2-UD was amplified with the primer BAT2$\mathrm{B}-\mathrm{F}(\mathrm{R})$ [containing the restriction site for I-SCEI (S) and homologous sequence $(\mathrm{R})$ of BAT2-A(SF)] and BAT2-B-R from plasmid YHERP1.0 $\triangle \mathrm{BAT} 2$. In addition, RS-HERP1.0$B A-P_{T E F 1}-A T F 1-T_{P G K 1}-B B$ fragment was amplified from the plasmid YHERP1.0 $\triangle$ BAT2::ATF1 by using the primers BAT2$\mathrm{B}-\mathrm{F}(\mathrm{R})$ and $\mathrm{YH} 1.0 \Delta \mathrm{B}: \mathrm{A}-\mathrm{R}$. The primers used in first step of integration of HERP1.0 cassette are shown in Table 2.

The fragments BAT2-A(RSF) and RS-HERP1.0-BAT2-UD were transformed into the yeast strain $\alpha 5$ by lithium acetate method and spread onto TPGly + AF plates, obtaining a mutant yeast $\mathrm{H} \alpha 5+\mathrm{H}$ (BAT2 deletion) with HERP1.0 integrant. Using the same method, fragments $B A T 2-A(R S F)$ and RS-HERP1.0-BA- $P_{T E F 1}-A T F 1-T_{P G K 1}-B B$ were transformed into the yeast strain $\alpha 5$ to construct mutant $\mathrm{H} \alpha 5:: \mathrm{ATF} 1+\mathrm{H}$ (BAT2 deletion and ATF1 overexpression) with HERP1.0 integrant.

2.4. Pop-Out of HERP1.0 Cassette through Second Step of Induction in Galactose. $\mathrm{H} \alpha 5+\mathrm{H}$ cells were incubated and induced in galactose medium at $30^{\circ} \mathrm{C}$ at $180 \mathrm{rpm}$. The ISCE1 endonuclease was expressed at I-SCE1 site, and DSB was generated and repaired through the second homologous recombination. The yeast solution after dilution was spread onto $\mathrm{SC}+\mathrm{FUdR}$. The resulting strain $\mathrm{H} \alpha 5$ popping out the 
TABLE 1: Strains and plasmids used in the current study.

\begin{tabular}{|c|c|c|}
\hline Strains or plasmids & Relevant characteristic & Reference or source \\
\hline \multicolumn{3}{|l|}{ Strains } \\
\hline $\mathrm{DH} 5 \alpha$ & supE44 $\Delta$ lac $\mathrm{U} 169(\varphi$ 80lacZ $\Delta \mathrm{M} 15)$ hsd $\mathrm{R} 17$ recAl end $\mathrm{Al}$ gyrA96 thil relA & This lab \\
\hline yWH245 & $\Delta a d e 2:: H E R P 1.0 \Delta l e u 2 \Delta$ ura3 $\Delta$ ho::KanMX & Gifted by William $\mathrm{G}$ \\
\hline$\alpha 5$ & MAT $\alpha$, haploid yeast strain from AY15 & This lab \\
\hline $\mathrm{H} \alpha 5(50)$ & 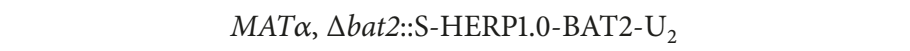 & This study \\
\hline $\mathrm{H} \alpha 5(150)$ & $M A T \alpha, \Delta b a t 2:: S-H E R P 1.0-B A T 2-\mathrm{U}_{3}$ & This study \\
\hline $\mathrm{H} \alpha 5(300)$ & $M A T \alpha, \Delta b a t 2:: S-H E R P 1.0-B A T 2-\mathrm{U}_{4}$ & This study \\
\hline $\mathrm{H} \alpha 5(500)$ & MAT $\alpha, \Delta$ bat2::S-HERP1.0-BAT2-U & This study \\
\hline $\mathrm{H} \alpha 5(700)$ & 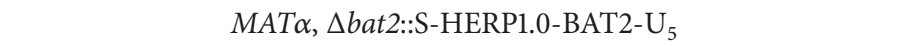 & This study \\
\hline $\mathrm{H} \alpha 5(1000)$ & $M A T \alpha, \Delta b a t 2:: S-H E R P 1.0-$ BAT2- $\mathrm{U}_{6}$ & This study \\
\hline $\mathrm{H} \alpha 5+\mathrm{H}$ & $M A T \alpha, \Delta b a t 2:: S-H E R P 1.0-B A T 2-U$ & This study \\
\hline $\mathrm{H} \alpha 5$ & $M A T \alpha, \Delta b a t 2$ & This study \\
\hline $\mathrm{H} \alpha 5:: \mathrm{ATF} 1+\mathrm{H}$ & $M A T \alpha, \Delta b a t 2:: \mathrm{S}-\mathrm{HERP} 1.0-\mathrm{BA}-\mathrm{P}_{\mathrm{TEF1}}-A T F 1-\mathrm{T}_{\mathrm{PGK} 1}$ & This study \\
\hline H $\alpha 5:: A T F 1$ & $M A T \alpha, \Delta b a t 2:: \mathrm{P}_{\mathrm{TEF} 1}-A T F 1-\mathrm{T}_{\mathrm{PGK} 1}$ & This study \\
\hline \multicolumn{3}{|l|}{ Plasmids } \\
\hline pUC19 & $\mathrm{Ap}^{\mathrm{r}}$, cloning vector & This lab \\
\hline Yep352 & $\mathrm{Ap}^{\mathrm{r}}$, ori control vector & This lab \\
\hline pUC-BBTAP & $A \mathrm{p}^{\mathrm{r}}$, containing $B A-P_{T E F 1}-A T F 1-T_{P G K 1}-B B$ cassette & This lab \\
\hline pUC19-UD & $\mathrm{Ap}^{\mathrm{r}}$, containing BAT2-UD cassette & This study \\
\hline YHERP1.0 & $\mathrm{Ap}^{\mathrm{r}}, \mathrm{TK}^{\mathrm{r}}$, containing HERP1.0 cassette & This study \\
\hline YHERP1.0 $\triangle$ BAT2 & $\mathrm{Ap}^{\mathrm{r}}, \mathrm{TK}^{\mathrm{r}}$, containing HERP1.0-BAT2-UD cassette & This study \\
\hline YHERP1.0(50 bp) & $\mathrm{Ap}^{\mathrm{r}}, \mathrm{TK}^{\mathrm{r}}$, containing HERP1.0-BAT2- $\mathrm{U}_{2} \mathrm{D}$ cassette & This study \\
\hline YHERP1.0(150 bp) & $\mathrm{Ap}^{\mathrm{r}}, \mathrm{TK}^{\mathrm{r}}$, containing HERP1.0-BAT2- $\mathrm{U}_{3} \mathrm{D}$ cassette & This study \\
\hline YHERP1.0(300 bp) & $\mathrm{Ap}^{\mathrm{r}}, \mathrm{TK}^{\mathrm{r}}$, containing HERP1.0-BAT2- $\mathrm{U}_{4} \mathrm{D}$ cassette & This study \\
\hline YHERP1.0(500 bp) & $\mathrm{Ap}^{\mathrm{r}}, \mathrm{TK}^{\mathrm{r}}$, containing HERP1.0-BAT2-UD cassette & This study \\
\hline YHERP1.0(700 bp) & $\mathrm{Ap}^{\mathrm{r}}, \mathrm{TK}^{\mathrm{r}}$, containing HERP1.0-BAT2- $\mathrm{U}_{5} \mathrm{D}$ cassette & This study \\
\hline YHERP1.0(1000 bp) & $\mathrm{Ap}^{\mathrm{r}}, \mathrm{TK}^{\mathrm{r}}$, containing HERP1.0-BAT2- $\mathrm{U}_{6} \mathrm{D}$ cassette & This study \\
\hline YHERP1.0 $\triangle$ BAT2::ATF1 & $\mathrm{Ap}^{\mathrm{r}}, \mathrm{TK}^{\mathrm{r}}$, containing HERP1.0-BA - $\mathrm{P}_{\mathrm{TEF1}}-A T F 1-\mathrm{T}_{\mathrm{PGK} 1}-\mathrm{BB}$ cassette & This study \\
\hline
\end{tabular}

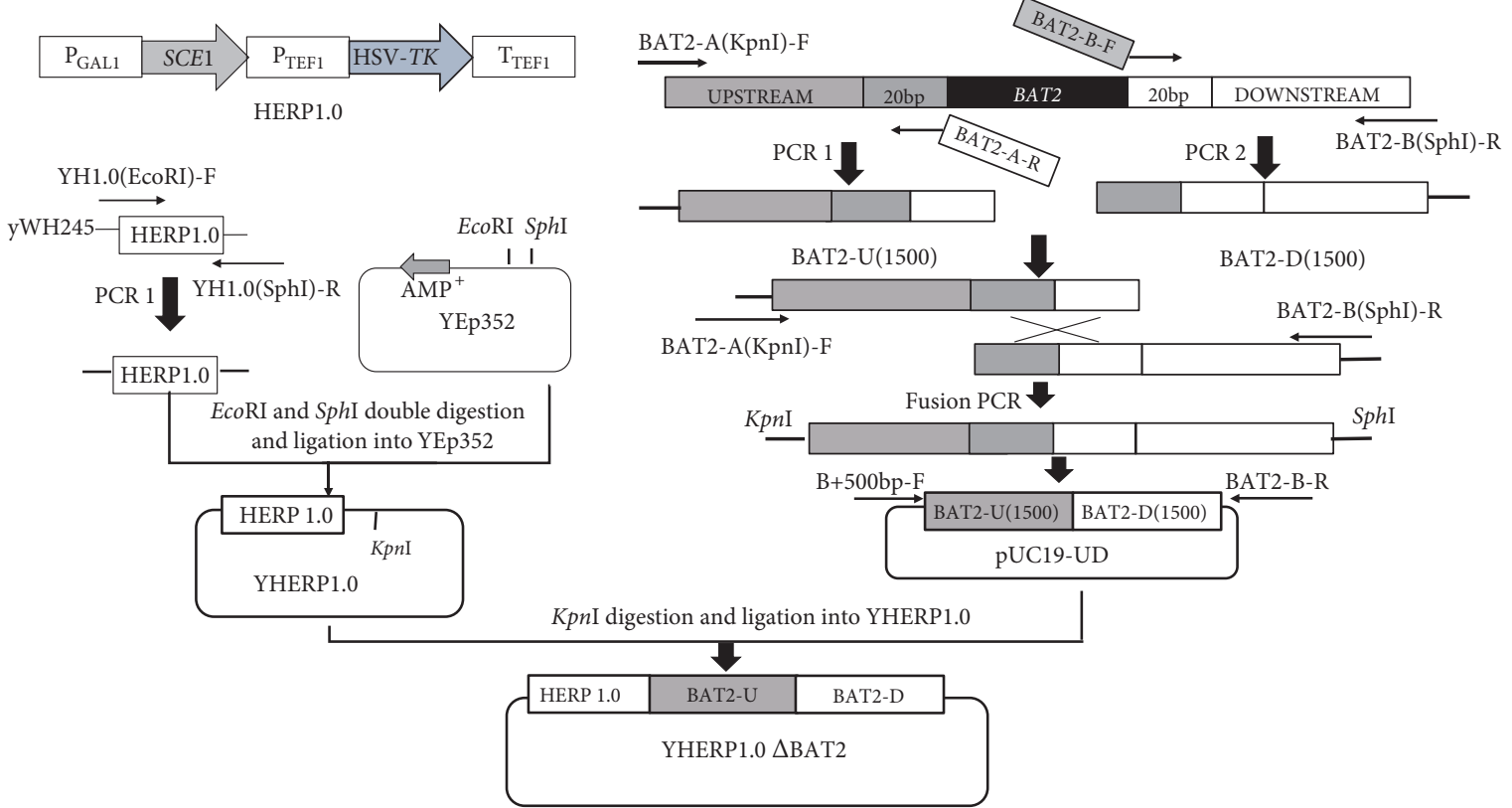

FIGURE 1: Construction of plasmid YHERP1.0ABAT2. 


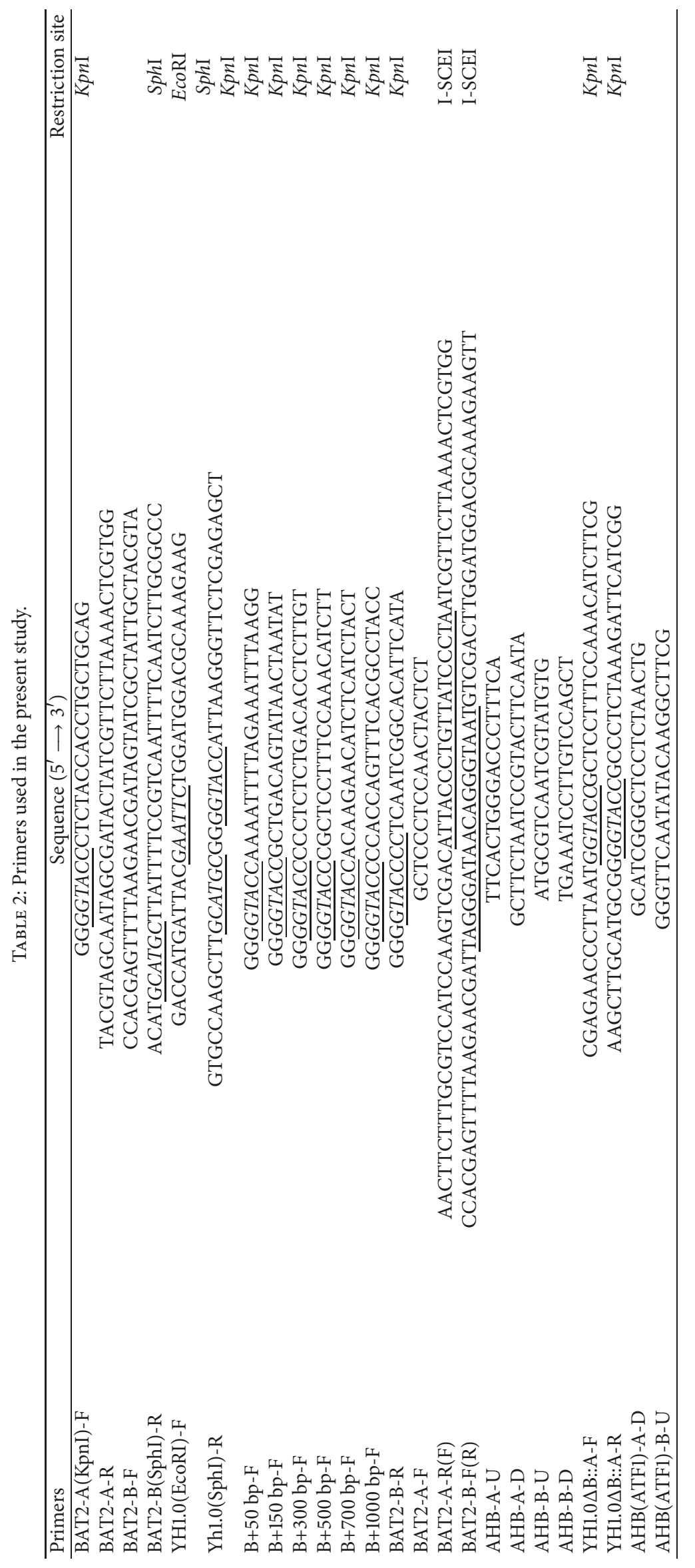




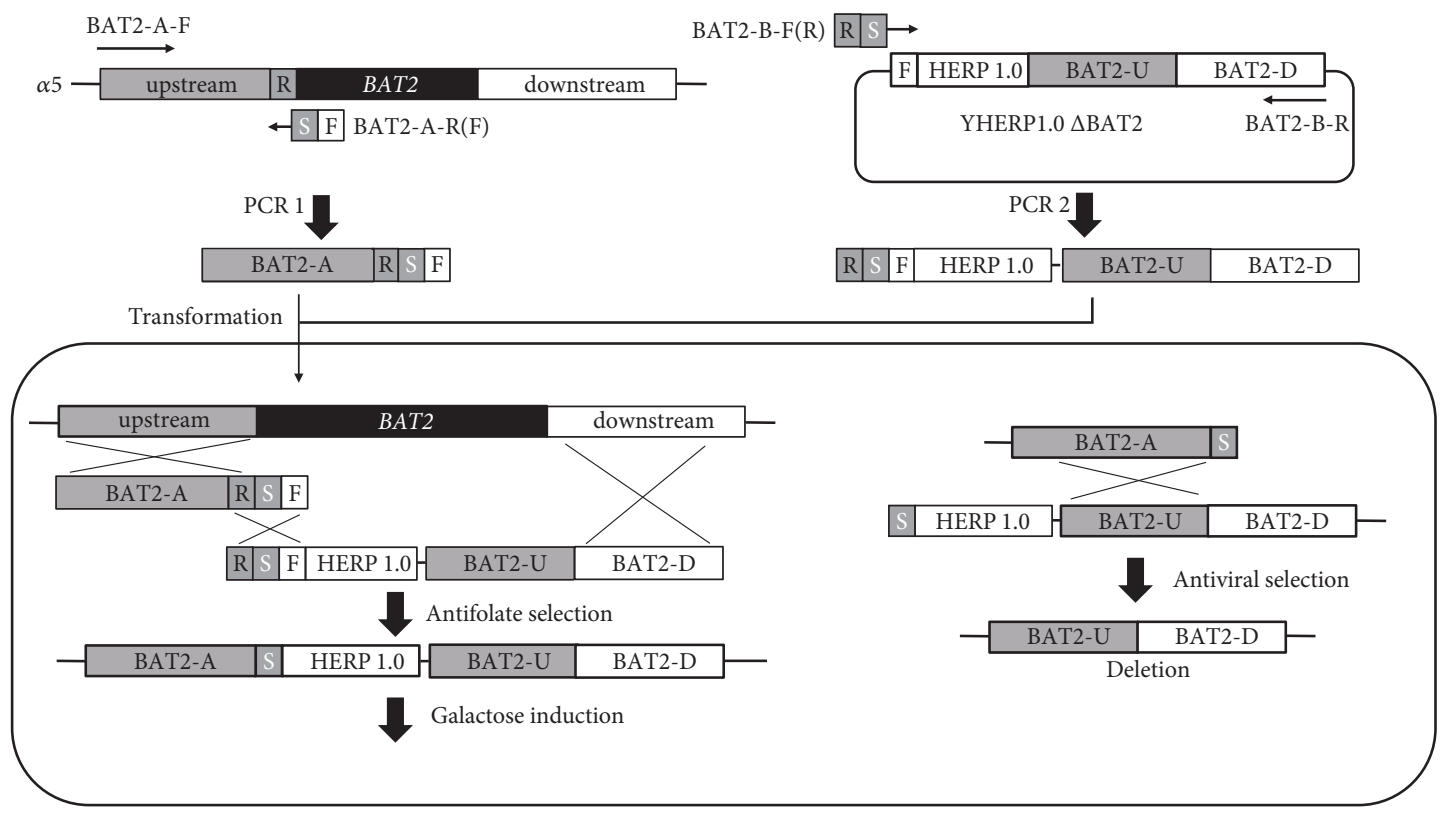

FIGURE 2: Schematic illustration of seamless deletion of BAT2 with two-step homologous recombination in Saccharomyces cerevisiae.

HERP1.0 integrant was constructed (Figure 2). The mutant H $\alpha 5:: A T F 1$ (BAT2 deletion and ATF1 overexpression) was constructed using the same processing step.

\subsection{Optimization of Factors Affecting Frequency of the Second} Homologous Recombination. Different lengths of DRs (50, $150,300,500,700$, and $1000 \mathrm{bp}$ ) were used to construct the plasmids YHERP1.0(50), YHERP1.0(150), YHERP1.0(300), YHERP1.0(500), YHERP1.0(700), and YHERP1.0(1000). The fragments RS-HERP1.0-BAT2-U (50, 150, 300, 500, 700, and 1000) D amplified from the plasmids YHERP1.0 (50, 150, $300,500,700$, and 1000) were transformed into the yeast strain $\alpha 5$ with the fragment BAT2-A-SF, thereby yielding the mutants $\mathrm{H} \alpha 5+\mathrm{H}(50,150,300,500,700$, and 1000$)$ that carry HERP1.0 integrants with different DR lengths. The mutants were induced in $0.1 \mathrm{~g} / 100 \mathrm{~mL}$ galactose for approximately 24 $\mathrm{h}$ and replica-plated onto TPGly $+\mathrm{AF}$ and YEPD plates.

Chromosomal DSBs were generated through I-SCEI endonuclease induction. To confirm the effect of galactoseinducible time on the frequency of the second homologous recombination efficiency, the mutants carrying the HERP1.0 integrant with $500 \mathrm{bp}$ DRs were induced in $0.1 \mathrm{~g} / 100 \mathrm{~mL}$ galactose medium for $12,24,36$, and $48 \mathrm{~h}$ and replica-plated onto TPGly + AF and YEPD plates. The counts of the mutants were measured in both plates.

The media with different galactose concentrations $(0.1$, $0.5,1,2,3,4$, and $5 \mathrm{~g} / 100 \mathrm{~mL}$ ) were used to induce I-SCEI endonuclease expression. The mutants carrying HERP1.0 integrant with $500 \mathrm{bp}$ DRs were induced in the galactose media for $24 \mathrm{~h}$ and replica-plated onto TPGly + AF and YEPD plates. The growth and characteristics of colonies cultured in TPGly + AF and YEPD plates were measured.

2.6. Fermentation Experiment. Corn hydrolysate medium was used in Baijiu fermentation of the parental strain and mutants. The details of the experiment procedures, including preparation of corn hydrolysate and control of the fermentation process, were based on those used in a previous study [31]. All fermentations were performed in triplicate.

2.7. Analytical Methods. $\mathrm{CO}_{2}$ weight loss during fermentation was determined using an analytical balance. Residual sugar, ethanol production, total acids, and total ester were detected after the fermentation was terminated using the standard method according to the International Organization of Vine and Wine [32]. The production of volatile flavor compounds including higher alcohols and esters was determined using Agilent 7890C GC through the method reported by $\mathrm{Ma}$ et al. [33].

2.8. Statistical Analysis. Data were represented as the mean \pm standard errors. The differences between the transformants and the parental strain were confirmed by Student's t-test. Statistical significance was considered at $P<0.05$.

\section{Results}

3.1. Construction of the Seamless Gene Deletion Method. In the current study, a seamless gene deletion system was constructed using the BAT2 gene as a target gene. In HERP1.0 cassette, TkMX was fused to the I-SCE1 gene driven by the galactose-inducible promoter of GAL1 by gap repair cloning in the strain. Fragments BAT2-A(RSF) and RS-HERP1.0$B A T 2-U D$ were transformed into the $\alpha 5$ chromosome to replace $B A T 2$ gene through the first homologous recombination. After galactose induction, DSBs by I-SCE1 endonuclease induction facilitated the second homologous recombination, and the HERP1.0 cassette was popped out. The process of deletion strategy is illustrated in Figures 1 and 2. 


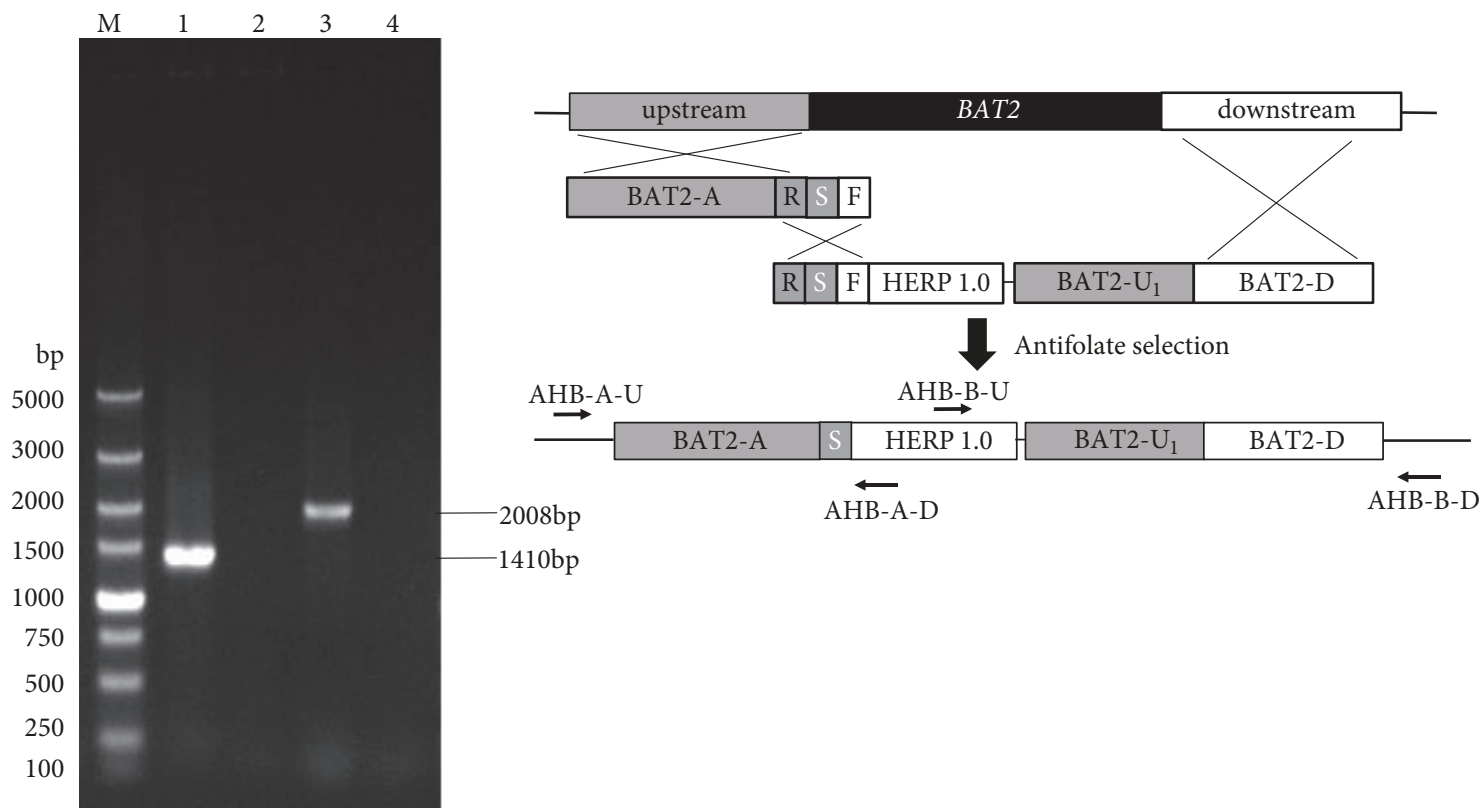

(a)

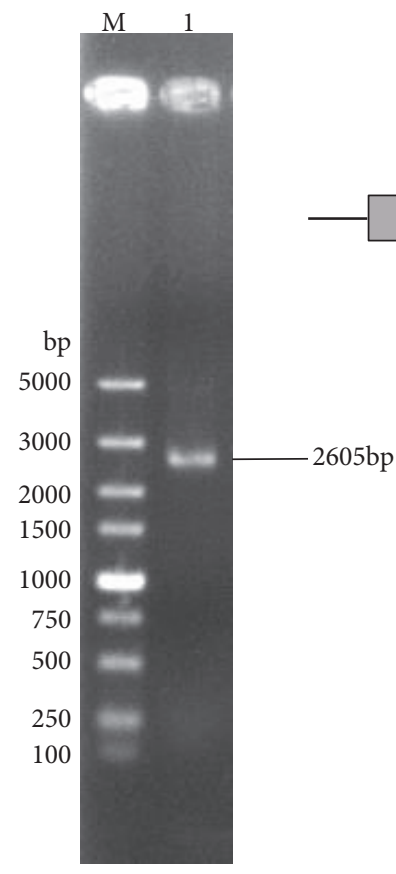

BAT2-A

\begin{tabular}{|l|l}
\hline$S$ & HERP 1.0
\end{tabular}

BAT2- $\mathrm{U}_{1}$

BAT2-D

Galactose induction

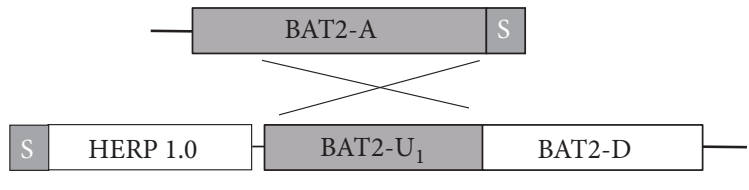

Antiviral selection

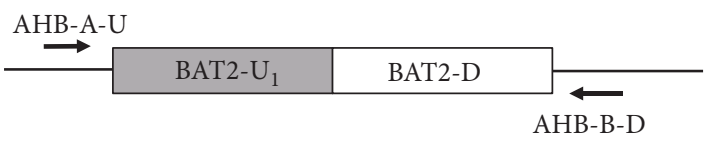

(b)

FIGURE 3: Colony PCR of integrants. (a) PCR verification of first step of integration of HERP1.0 cassette. (b) PCR verification of pop-out of HERP1.0 cassette.

After transformation of fragments $B A T 2-A(R S F)$ and RS-HERP1.0-BAT2-UD, the correct mutant $\mathrm{H} \alpha 5+\mathrm{H}(B A T 2$ deletion) with HERP1.0 integrant was selected on TPGly + AF plates. PCR amplification with specific primers (AHB-A$\mathrm{U}$ and AHB-A-D, AHB-B-U, and AHB-B-D) from genomic DNA of desired mutant strains produced a $1410 \mathrm{bp}$ band (Figure 3(a), lane 2) and a 2008 bp band. Moreover, no amplification (Figure 3(a), lane 1) was observed from the parental strain $\alpha 5$. The fragments BAT2-A(RSF) and RS-HERP1.0$B A T 2-U D$ were integrated at the target site of genome in $S$. cerevisiae $\alpha 5$.

$\mathrm{H} \alpha 5+\mathrm{H}$ cells were cultivated and induced in galactose medium and then replica-plated onto SC + FUdR plates. Only strains in which the HERP1.0 integrant was popped out can grow on SC + FUdR plates. The deletion strains were further confirmed via PCR by using the primer pairs 


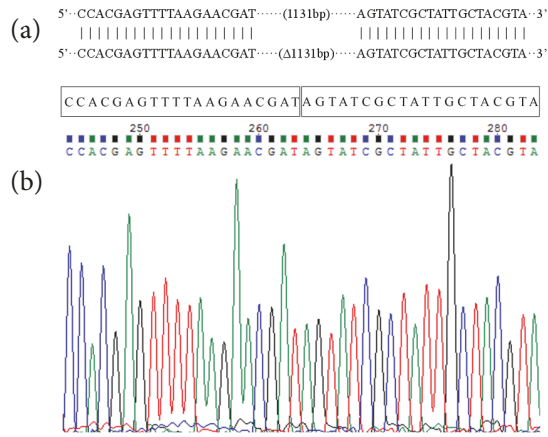

FIGURE 4: Sequence alignment and sequencing results of the adjacent region of BAT2 after pop-out of HERP1.0 cassette. (a) Comparison of the sequences before (above) and after (below) deletion. (b) Sequencing results of deletion.

of AHB-A-U and AHB-B-D. A 2605 bp band (Figure 3(b), lane 1) containing no HERP1.0 region was obtained, demonstrating that the strain $\mathrm{H} \alpha 5$ with BAT2 seamless deletion was constructed successfully. In addition, the sequence alignment was detected, and the sequencing results illustrated in Figure 3 are consistent with the S288C genomic sequence from the Saccharomyces Genome Database (SGD, accession number 9169867). The $1131 \mathrm{bp}$ sequence containing the gene $B A T 2$ region of genome was completely deleted, and no foreign DNA sequence was retained in the $S$. cerevisiae chromosome (Figure 4, part of results).

3.2. Effect of the Factors on Frequency of the Second Homologous Recombination Efficiency. Different lengths of DRs $(50,150,300,500,700$, and $1000 \mathrm{bp})$ were used to detect the second homologous recombination efficiency. The first homologous recombination, in which mutants $\mathrm{H} \alpha 5+\mathrm{H}$ (50, $150,300,500,700$, and 1000) carrying HERP1.0 integrants with different lengths of DRs were constructed, was verified via PCR by using primer pairs of AHB-A-U and AHB-A-D and AHB-B-U and AHB-B-D (Figure 5). Regarding galactose induction, the second homologous recombination was performed, and the counts of yeast colonies were measured in TPGly + AF and YEPD plates. The result is shown in Figure 6(a). When the DR length was less than $500 \mathrm{bp}$, the second homologous recombination efficiency increased with increasing DR length but showed no obvious distinction when the DR length exceeded $700 \mathrm{bp}$. The desired deletion occurred at a frequency of approximately $4.74 \times 10^{-4}$ at the optimal length (500 bp) of DRs.

Mutant strains carrying HERP1.0 integrant with $500 \mathrm{bp}$ DRs were induced in galactose for $12,24,36$, and $48 \mathrm{~h}$ to confirm the effect of galactose-inducible time on chromosomal DSBs. The count of the mutants was measured in TPGly + AF and YEPD plates. Figure 6(b) shows that the second homologous recombination efficiency increased with increasing of galactose induction time. Meanwhile, long experimental time has a direct effect on experimental period. The induction time of $24 \mathrm{~h}$ was chosen as the optimal induction time, and the second homologous recombination efficiency was $4.62 \times 10^{-4}$.

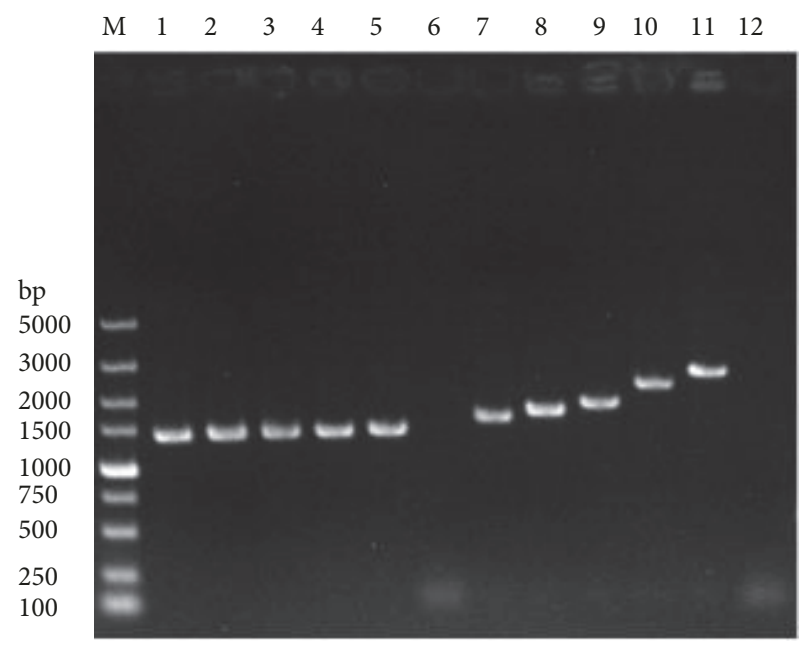

FIGURE 5: PCR verification of mutant strains $H \alpha 5+H(50,150,300$, 700, 1000). M DL5000 DNA marker; lanes 1-lanes 6 PCR verification results from mutant strains $\mathrm{H} \alpha 5+\mathrm{H}(50), \mathrm{H} \alpha 5+\mathrm{H}(150), \mathrm{H} \alpha 5+\mathrm{H}$ (300), $\mathrm{H} \alpha 5+\mathrm{H}$ (700), $\mathrm{H} \alpha 5+\mathrm{H}(1000)$, parental strain, respectively, using primer pairs AHB-A-U and AHB-A-D; lanes 7-lanes 12 PCR verification results from mutant strains $\mathrm{H} \alpha 5+\mathrm{H}(50), \mathrm{H} \alpha 5+\mathrm{H}$ (150), $\mathrm{H} \alpha 5+\mathrm{H}$ (300), $\mathrm{H} \alpha 5+\mathrm{H}$ (700), $\mathrm{H} \alpha 5+\mathrm{H}$ (1000), parental strain, respectively, using primer pairs AHB-B-U and AHB-B-D.

As the I-SCEI endonuclease expression was affected by galactose concentration, mutants carrying HERP1.0 integrant with 500 bp DRs were induced in media with different galactose concentrations. The colonies in TPGly $+\mathrm{AF}$ and YEPD plates were counted. The result in Figure 6(c) demonstrates that the galactose content had a significant effect on the second homologous recombination. At the galactose concentrations of 0.1 and $0.5 \mathrm{~g} / 100 \mathrm{~mL}$, the second homologous recombination efficiencies were $4.66 \times 10^{-4}$ and $6.86 \times 10^{-4}$, respectively, showing an increased tendency. However, when the content was in the range of $1 \mathrm{~g} / 100 \mathrm{~mL}$ to $5 \mathrm{~g} / 100 \mathrm{~mL}$, the second homologous recombination efficiency decreased. The $0.5 \mathrm{~g} / 100 \mathrm{~mL}$ content was chosen as the optimal condition to induce the I-SCEI endonuclease expression to generate chromosomal DSBs.

\subsection{Regulation of BAT2 Seamless Deletion and ATF1 Overex-} pression on Higher Alcohols and Ester in Baijiu S. cerevisiae. Branched-chain alcohols are products from the degradation of corresponding branched-chain amino acids (BCAAs). BCAAs are converted to the corresponding $\alpha$-keto acids through the initial transamination step, which is catalyzed by the aminotransferases (encoded by BAT2) [34]. Alcohol acetyltransferase encoded by gene ATF1 (known as AATaseI or Atflp) is a key enzyme in the synthesis of acetate ester, which is one of the major beneficial esters and responsible for the highly desired fruity aroma in Baijiu. Thus, fragment $P_{T E F 1}-A T F 1-T_{P G K 1}$, in which the $A T F 1$ gene was overexpressed under the control of the TEF1 promoter, was inserted into the locus of BAT2 gene to construct the strain $\mathrm{H} \alpha 5$ ::ATF1 with BAT2 gene deletion and ATF1 gene overexpression. 


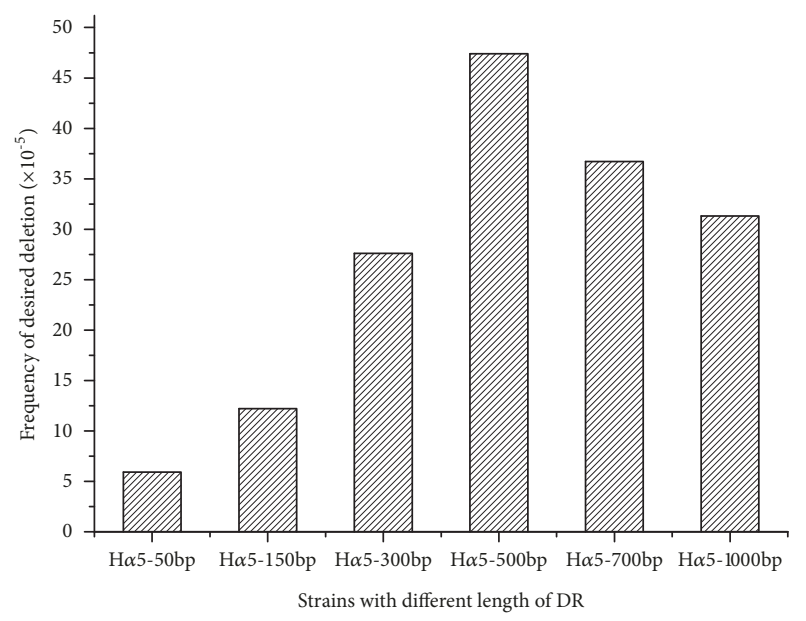

(a)

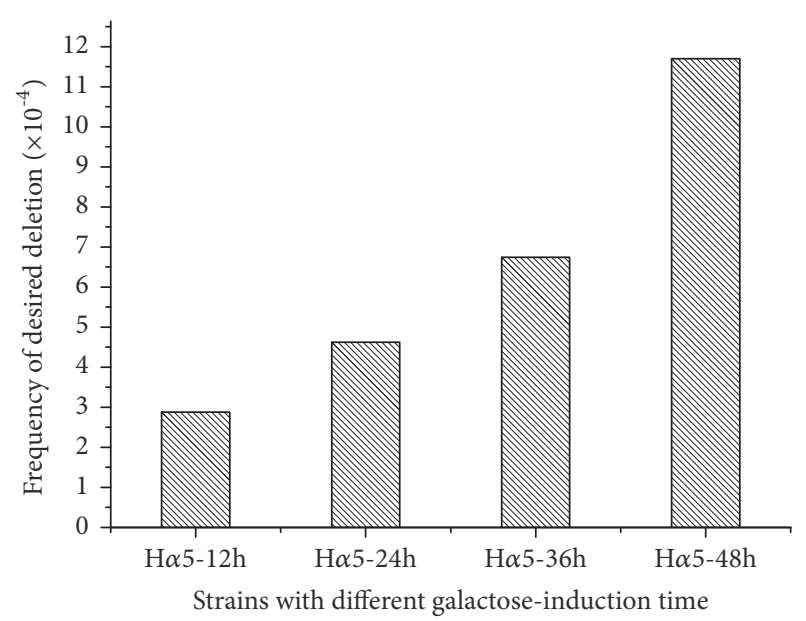

(b)

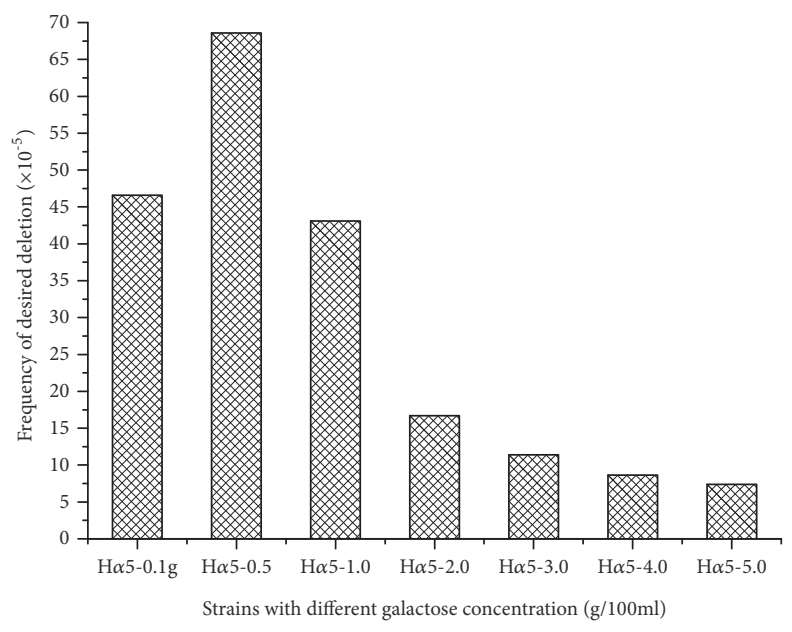

(c)

Figure 6: The effect of the length of DRs (a), induction time in galactose (b), and galactose concentration (c) on frequency of the second homologous recombination efficiency.

The mutant strains $\mathrm{H} \alpha 5$ (BAT2 gene deletion) and $\mathrm{H} \alpha 5:: \mathrm{ATF} 1$ (BAT2 gene deletion and ATF1 gene overexpression) were fermented in Baijiu in contrast with the parental strain. Moreover, the production of higher alcohols and esters were detected after fermentation to confirm the effect of the mutants $\mathrm{H} \alpha 5$ and $\mathrm{H} \alpha 5:: \mathrm{ATF} 1$ on the regulation of higher alcohols and esters (Figure 7). No obvious distinctions were obtained in acetate esters and $\beta$-phenylethanol content of the parental strain and $\mathrm{H} \alpha 5(P>0.05)$. The production of n-propanol, isobutanol, and isoamylol by $\mathrm{H} \alpha 5$ were 24.25 , 48.26 , and $162.65 \mathrm{mg} / \mathrm{L}$, which decreased by $20.32 \%, 44.92 \%$, and $26.64 \%$, respectively, compared with those of the parental strain $(30.44,87.62$, and $221.70 \mathrm{mg} / \mathrm{L}, P<0.05)$. This result showed the significant effects on higher alcohol reduction. The concentration of ethyl acetate by $\mathrm{H} \alpha 5:$ :ATF1 was 920.05 $\mathrm{mg} / \mathrm{L}$, which was 34.84 -fold higher than that produced by parental strain $\alpha 5(25.68 \mathrm{mg} / \mathrm{L}, P<0.05)$. Moreover, the content of isobutyl acetate and isoamyl acetate increased to 12.43 and $60.38 \mathrm{mg} / \mathrm{L}$, respectively. The $\beta$-phenylethanol, isobutanol, and isoamylol contents produced by $\mathrm{H} \alpha 5:$ ATF1 were $21.15 \%(52.32 \mathrm{mg} / \mathrm{L}$ in the parental strain and 41.25 $\mathrm{mg} / \mathrm{L}$ in $\mathrm{H} \alpha 5:$ ATF1, $P<0.05$ ), $57.85 \%$ (87.62 $\mathrm{mg} / \mathrm{L}$ in the parental strain and $36.93 \mathrm{mg} / \mathrm{L}$ in $\mathrm{H} \alpha 5:: A T F 1, P<0.05)$ and $60.36 \%(221.70 \mathrm{mg} / \mathrm{L}$ in the parental strain and 87.86 $\mathrm{mg} / \mathrm{L}$ in $\mathrm{H} \alpha 5:: \mathrm{ATF} 1, P<0.05)$ less than those produced by parental strain $\alpha 5$. Moreover, compared with mutant $\mathrm{H} \alpha 5$, the isobutanol and isoamylol contents by $\mathrm{H} \alpha 5:$ :ATF1 decreased by $23.48 \%(48.26 \mathrm{mg} / \mathrm{L}$ in $\mathrm{H} \alpha 5, P<0.05)$ and $45.98 \%(162.65$ $\mathrm{mg} / \mathrm{L}$ in $\mathrm{H} \alpha 5, P<0.05)$, respectively. This result demonstrated that the mutant strain $\mathrm{H} \alpha 5:: A T F 1$ had significant effect not only on higher alcohol reduction but also on acetate ester improvement in S. cerevisiae.

3.4. Fermentation Properties of the Mutant Strains. Stable and credible performance of the strains is remarkably important for Baijiu fermentation. The fermentation properties, including weight loss of $\mathrm{CO}_{2}$, liquor yield, residual sugar, total acids, and total esters, were investigated to assess the 


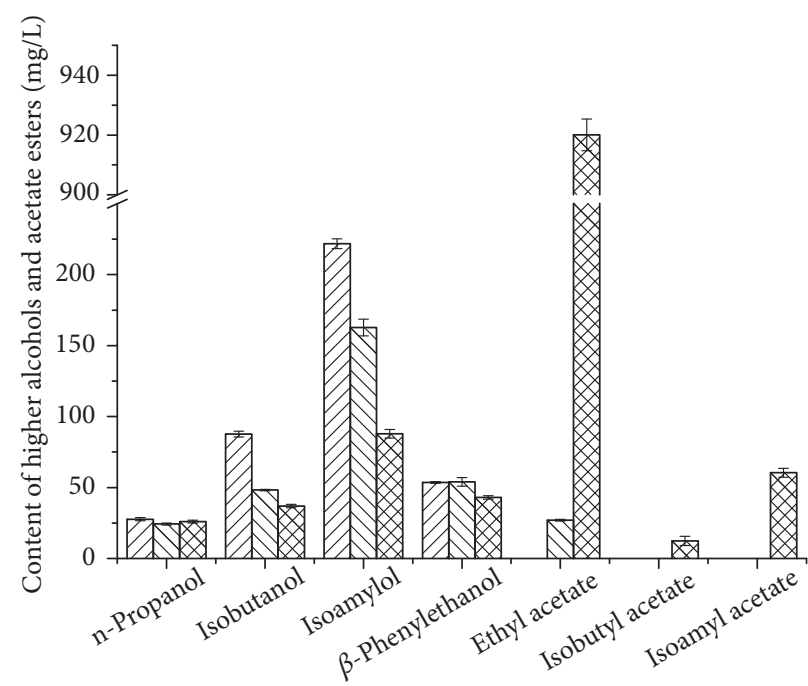

DZ7 $\alpha 5$

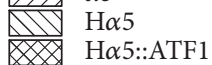

FIGURE 7: Higher alcohols and esters production of the recombinant strains and parental strain in Baijiu. Data are the average of three independent experiments. Error bars represent \pm SD.

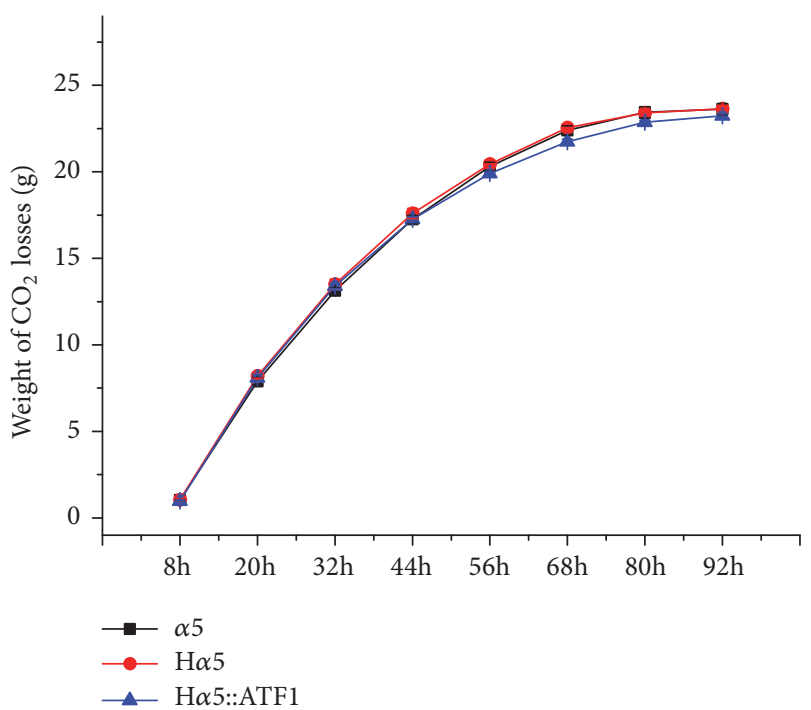

FIGURE 8: Weight loss of mutant strains and parental strain during small-scale Baijiu fermentation. Data are the average of three independent experiments. Error bars represent \pm SD.

stable performance of the mutants with BAT2 deletion and $A T F 1$ overexpression. Weight loss was monitored during fermentation (Figure 8). $\mathrm{H} \alpha 5$ showed the same weight loss trend with the parental strain, whereas the fermentation rate of mutant $\mathrm{H} \alpha 5:: \mathrm{ATF} 1$ was slightly slower than that of strain $\alpha 5$. However, the mutants had no significant difference in terms of total weight loss of $\mathrm{CO}_{2}$ compared with the parental strain $(P>0.05)$. The ethanol content, residual sugar, total acids, and total esters were detected after fermentation (Table 3). No obvious distinction was observed in the ethanol content, residual sugar, total acids, and total esters of the parental strain and $\mathrm{H} \alpha 5(P>0.05)$. Meanwhile, the content of ethanol and total acids in $\mathrm{H} \alpha 5:: \mathrm{ATF} 1$ decreased by $2.25 \%$ $(16.03 \% \mathrm{v} / \mathrm{v}$ in parental strain and $15.67 \% \mathrm{v} / \mathrm{v}$ in $\mathrm{H} \alpha 5:: \mathrm{ATF} 1$, $P<0.05)$ and $19.35 \%$ (0.093 $\mathrm{g} / \mathrm{L}$ total acids in parental strain, and $0.075 \mathrm{~g} / \mathrm{L}$ total acids in $\mathrm{H} \alpha 5:: \mathrm{ATF} 1, P<0.05)$. Moreover, the total ester content increased by $111.35 \%(0.705 \mathrm{~g} / \mathrm{L}$ in the parental strain and $1.490 \mathrm{~g} / \mathrm{L}$ in $\mathrm{H} \alpha 5:: A T F 1, P<0.05)$ compared with those of parental strain $\alpha 5$.

\section{Discussion}

S. cerevisiae plays a major role in traditional biotechnologies, such as baking, brewing, and wine making. Its broad application in industry is closely related to its role as a major platform for metabolic engineering that aims to enhance yeast biotechnology. Thus, the application of gene-modified technology in genome editing of $S$. cerevisiae is necessary for promoting its efficacy and safety in industry. Many current tools for gene manipulation in $S$. cerevisiae are still limited in terms of generation of the disruption construct or in the efficiency of transformation or marker removal. This study developed a rapid and highly efficient protocol for genome editing allowing gene disruption without any exogenous gene in $S$. cerevisiae. HERP1.0 cassette, including the TkMX marker and a galactose-inducible I-SCE1 endonuclease, was fused into a fusion DNA fragment of the upstream and the downstream sequences with an I-SCE1 site and then transformed into the $S$. cerevisiae $\alpha 5$ with an upstream sequence of target gene. The HERP1.0 cassette and the DR were inserted into the locus of the target gene after the first homologous recombination. The DSB was generated at the I-SCE1 site under the induction of galactose and repaired through the second homologous recombination of DRs. Meanwhile, sequence analysis of the target region revealed that the HERP1.0 sequences were removed completely. The method is more effective than the two-step integration protocol described by Dong et al., in which wild-type $U R A 3$ in host strain was replaced by a disabled ura3 gene before deletion, and the resulting mutants of the second integration recombination of DRs were either parental or deletion strains [35]. In the current method, the TKMX gene that has not been identified in fungus to date was used as a selectable and counter-selectable marker, and the final mutant was only the desired deletion strain. As the mutant left only self-DNA in its native location without any foreign DNA sequence after deletion, the current strategy can be repeatedly used in yeast strains.

The desired deletion strain was obtained through the second homologous recombination after galactose induction. The length of DRs, induction time, and galactose concentration were the crucial factors that affect the frequency of the second homologous recombination efficiency. The length of DRs has a direct correlation with the DSB. In Rinji AKada's research, a 40 bp sequence derived from a region adjacent to the targeted locus was placed in an integrating construct to generate DRs after integration, and the recombination frequency $\left(10^{-6}\right)$ was low [17]. Thus, $500 \mathrm{bp}$ was chosen as the optimal length of DRs to promote the second homologous recombination in the desired deletion in this study. 
TABLE 3: The alcohol and residual sugar content fermented by the parental strain and engineered strains ${ }^{a}$.

\begin{tabular}{lcccc}
\hline Strains & Alcohol content $(\%, \mathrm{v} / \mathrm{v})$ & Residual sugar $(\mathrm{g} / \mathrm{L})$ & Total acids $(\mathrm{g} / \mathrm{L})$ & Total esters $(\mathrm{g} / \mathrm{L})$ \\
\hline$\alpha 5$ & $16.03 \pm 0.15$ & $2.04 \pm 0.12$ & $0.093 \pm 0.012$ & $0.705 \pm 0.009$ \\
$\mathrm{H} \alpha 5$ & $16.12 \pm 0.11$ & $2.88 \pm 0.10$ & $0.100 \pm 0.015$ & $0.629 \pm 0.011$ \\
$\mathrm{H} \alpha 5::$ ATF1 & $15.67 * \pm 0.10$ & $3.01 \pm 0.08$ & $0.075 * \pm 0.010$ & $1.490 * \pm 0.015$ \\
\hline
\end{tabular}

${ }^{a}$ Data are the average of three independent experiments \pm the standard deviation. Significant difference of H $\alpha 5:: A T F 1$ from the parental strain was confirmed by Student's $t$-test $(* P<0.05, \mathrm{n}=3)$.

Furthermore, the induction time and galactose concentration during galactose induction affected the expression of the I-SCE1 endonuclease and then influenced the DSB repair through homologous recombination. Considering the period and efficiency of the experiment, $24 \mathrm{~h}$ and $0.5 \mathrm{~g} / 100 \mathrm{~mL}$ were chosen as the optimal induction time and galactose concentration, respectively.

Aminotransferase encoded by BAT2 and alcohol acetyltransferases encoded by ATF1 are related to the metabolism of branched-chain alcohols and acetate esters, respectively. The strain $\mathrm{H} \alpha 5$ with $B A T 2$ deletion and $\mathrm{H} \alpha 5:$ :ATF1 with $B A T 2$ deletion and $A T F 1$ overexpression were engineered using the current method. The higher alcohol contents, specifically $n$-propanol, isobutanol, and isoamylol contents, decreased significantly after BAT2 gene deletion in mutant $\mathrm{H} \alpha 5$. The result was consistent with the conclusion obtained in our previous research [36]. ATF1 gene encoding alcohol acetyltransferases was overexpressed under the control of promoter TEF1 at the locus of the BAT2 in this work. The acetate ester concentrations produce by the mutant $\mathrm{H} \alpha 5:$ :ATF1 had obvious increase compared with those of the parental strain, and the higher alcohols, such as isobutanol, $\beta$-phenylethanol, and isoamylol production, were further decreased compared with the mutant $\mathrm{H} \alpha 5$. This result demonstrated that ATF1 overexpression contributed not only in the reduction of higher alcohol production but also in the improvement of the acetate ester contents. The result was in accordance with our previous study, in which the ATF1 gene was overexpressed under the control of the promoter $P G K 1$ and inserted into the BAT2 locus with KanMX maker, whereas excision of $\operatorname{KanMX}$ maker left behind the foreign sequences (a single loxP site) [5]. In this study, the mutants were constructed with BAT2 deletion and ATF1 overexpression via the seamless gene deletion system, in which TKMX gene was used as a selectable and counter-selectable marker. No any foreign DNA sequence retained in S. cerevisiae chromosome after deletion, thereby increasing the security of the engineered strains in industry.

\section{Conclusions}

A rapid and highly efficient system for seamless gene deletion through endonuclease I-SCEI as a DSB inducer and twostep integration protocol was developed. To accelerate the system efficiency, the factors affecting the frequency of the second homologous recombination efficiency were screened and optimized. In addition, the strains with BAT2 deletion and $A T F 1$ overexpression were constructed through the novel method, resulting in desirable reduction of higher alcohol contents and improvement of the acetate ester production. The novel protocol proposed in this work is a promising strategy for gene deletion in S. cerevisiae, providing insights into further improvement of performance characteristics of S. cerevisiae. Moreover, as any foreign genes did not retain at chromosomes after deletion, the engineered strains can be used in industrial production in security, easing public safety concerns over genetic modification and meeting the requirement of modern science and technology and industrial production.

\section{Data Availability}

The data used to support the findings of this study are available from the corresponding author upon request.

\section{Ethical Approval}

This manuscript is in compliance with Ethical Standards. This manuscript does not contain any studies with human participants or animals performed by any of the authors.

\section{Conflicts of Interest}

The authors declare that they have no conflicts of interest.

\section{Acknowledgments}

We are grateful to William G. Alexander for providing the strain yWH245 and the technical advice on the use of the HERP1.0 cassettes. The current study was financially supported by the National Key Research and Development Program of China (2016YFD0400505), the National Natural Science Foundation of China (No. 31771969), the Key Laboratory of Wuliangye-flavor Liquor Solid-state Fermentation, China National Light Industry (No. 2018JJ004), and the Innovative Research Team of Tianjin Municipal Education Commission (TD13-5013).

\section{References}

[1] E. Nevoigt, "Progress in metabolic engineering of Saccharomyces cerevisiae," Microbiology and Molecular Biology Reviews, vol. 72, no. 3, pp. 379-412, 2008.

[2] D. Schuller and M. Casal, "The use of genetically modified Saccharomyces cerevisiae strains in the wine industry," Applied Microbiology and Biotechnology, vol. 68, no. 3, pp. 292-304, 2005. 
[3] J. Zaldivar, A. Borges, B. Johansson et al., "Fermentation performance and intracellular metabolite patterns in laboratory and industrial xylose-fermenting Saccharomyces cerevisiae," Applied Microbiology and Biotechnology, vol. 59, no. 4-5, pp. 436-442, 2002.

[4] W. Fan and M. C. Qian, "Characterization of aroma compounds of Chinese "Wuliangye" and "Jiannanchun" liquors by aroma extract dilution analysis," Journal of Agricultural and Food Chemistry, vol. 54, no. 7, pp. 2695-2704, 2006.

[5] W. Li, J. H. Wang, C. Y. Zhang et al., "Regulation of Saccharomyces cerevisiae genetic engineering on the production of acetate esters and higher alcohols during Chinese Baijiu fermentation," Journal of Industrial Microbiology Biotechnology, vol. 44, no. 6, pp. 949-960, 2017.

[6] J. H. Swiegers and I. S. Pretorius, "Yeast modulation of wine flavor," Advances in Applied Microbiology, vol. 57, no. 57, pp. 131175, 2005.

[7] D. Yang, X. Luo, and X. Wang, "Characteristics of traditional Chinese shanlan wine fermentation," Journal of Bioscience and Bioengineering, vol. 117, no. 2, pp. 203-207, 2014.

[8] C. Zhang, Y. Liu, Y. Qi et al., "Increased esters and decreased higher alcohols production by engineered brewer's yeast strains," European Food Research and Technology, vol. 236, no. 6, pp. 1009-1014, 2013.

[9] R. Pöhlmann and P. Philippsen, "Sequencing a cosmid clone of Saccharomyces cerevisiae chromosome XIV reveals 12 new open reading frames (ORFs) and an ancient duplication of six ORFs," Yeast, vol. 12, no. 4, pp. 391-402, 1996.

[10] E. A. Winzeler, D. D. Shoemaker, A. Astromoff et al., "Functional characterization of the S. cerevisiae genome by gene deletion and parallel analysis," Science, vol. 285, no. 5429, pp. 901-906, 1999.

[11] W. G. Alexander, "A history of genome editing in Saccharomyces cerevisiae," Yeast, vol. 35, no. 5, pp. 355-360, 2018.

[12] A. Baudin, O. Ozier-kalogeropoulos, A. Denouel, F. Lacroute, and C. Cullin, "A simple and efficient method for direct gene deletion in Saccharomyces cerevisiae," Nucleic Acids Research, vol. 21, no. 14, pp. 3329-3330, 1993.

[13] H. Hao, X. Wang, H. Jia et al., "Large fragment deletion using a CRISPR/Cas9 system in Saccharomyces cerevisiae," Analytical Biochemistry, vol. 509, pp. 118-123, 2016.

[14] J. H. Hegemann, S. B. Heick, J. Pöhlmann, M. M. Langen, and U. Fleig, "Targeted gene deletion in Saccharomyces cerevisiae and Schizosaccharomyces pombe," Methods in Molecular Biology, vol. 1163, pp. 45-73, 2014.

[15] D. Landgraf, D. Huh, E. Hallacli, and S. Lindquist, "Scarless gene tagging with one-step transformation and two-step selection in Saccharomyces cerevisiae and Schizosaccharomyces pombe," Plos One, vol. 11, no. 10, Article ID e0163950, 2016.

[16] Q. Liu, H. Liu, Y. Yang et al., "Scarless gene deletion using mazF as a new counter-selection marker and an improved deletion cassette assembly method in Saccharomyces cerevisiae," The Journal of General and Applied Microbiology, vol. 60, no. 2, pp. 89-93, 2014.

[17] R. Akada, T. Kitagawa, S. Kaneko et al., "PCR-mediated seamless gene deletion and marker recycling in Saccharomyces cerevisiae," Yeast, vol. 23, no. 5, pp. 399-405, 2006.

[18] F. Fang, K. Salmon, M. W. Y. Shen et al., "A vector set for systematic metabolic engineering in Saccharomyces cerevisiae," Yeast, vol. 28, no. 2, pp. 123-136, 2011.
[19] A. E. Griep, M. C. John, S. Ikeda, and A. Ikeda, "Gene targeting in the mouse," Endocrine, vol. 19, no. 3, pp. 229-238, 2002.

[20] S. Ikushima, T. Fujii, and O. Kobayashi, "Efficient gene disruption in the high-ploidy yeast Candida utilis using the Cre-loxP system," Bioscience, Biotechnology, and Biochemistry, vol. 73, no. 4, pp. 879-884, 2009.

[21] T. Iwaki and K. Takegawa, "A set of loxP marker cassettes for cre-mediated multiple gene disruption in Schizosaccharomyces pombe," Bioscience, Biotechnology, and Biochemistry, vol. 68, no. 3, pp. 545-550, 2004.

[22] L. Cong, F. A. Ran, D. Cox et al., "Multiplex genome engineering using CRISPR/Cas systems," Science, vol. 339, no. 6121, pp. 819823, 2013.

[23] P. Mali, L. Yang, K. M. Esvelt et al., "RNA-guided human genome engineering via Cas9," Science, vol. 339, no. 6121, pp. 823-826, 2013.

[24] R. Mans, H. M. van Rossum, M. Wijsman et al., "CRISPR/Cas9: a molecular Swiss army knife for simultaneous introduction of multiple genetic modifications in Saccharomyces cerevisiae," FEMS Yeast Research, vol. 15, no. 2, p. fov004, 2015.

[25] T. J. Cradick, E. J. Fine, C. J. Antico, and G. Bao, "CRISPR/Cas9 systems targeting $\beta$-globin and CCR5 genes have substantial off-target activity," Nucleic Acids Research, vol. 41, no. 20, pp. 9584-9592, 2013.

[26] H. Deveau, R. Barrangou, J. E. Garneau et al., "Phage response to CRISPR-encoded resistance in Streptococcus thermophilus," Journal of Bacteriology, vol. 190, no. 4, pp. 1390-1400, 2008.

[27] S. H. Sternberg, S. Redding, M. Jinek, E. C. Greene, and J. A. Doudna, "DNA interrogation by the CRISPR RNA-guided endonuclease Cas9," Nature, vol. 507, no. 7490, pp. 62-67, 2014.

[28] L. Glover and D. Horn, "Site-specific DNA double-strand breaks greatly increase stable transformation efficiency in Trypanosoma brucei," Molecular and Biochemical Parasitology, vol. 166, no. 2, pp. 194-197, 2009.

[29] F. Storici, C. L. Durham, D. A. Gordenin, and M. A. Resnick, "Chromosomal site-specific double-strand breaks are efficiently targeted for repair by oligonucleotides in yeast," Proceedings of the National Acadamy of Sciences of the United States of America, vol. 100, no. 25, pp. 14994-14999, 2003.

[30] W. G. Alexander, D. T. Doering, and C. T. Hittinger, "Highefficiency genome editing and allele replacement in prototrophic and wild strains of saccharomyces," Genetics, vol. 198, no. 3, pp. 859-866, 2014.

[31] W. Li, S.-J. Chen, J.-H. Wang et al., "Genetic engineering to alter carbon flux for various higher alcohol productions by Saccharomyces cerevisiae for Chinese Baijiu fermentation," Applied Microbiology and Biotechnology, vol.102, no. 4, pp. 17831795, 2018.

[32] OIV, Compendium of International Methods of Wine and Must Analysis, International Organisation of Vine and Wine, Paris, France.

[33] L. Ma, S. Huang, L. Du, P. Tang, and D. Xiao, "Reduced Production of Higher Alcohols by Saccharomyces cerevisiae in Red Wine Fermentation by Simultaneously Overexpressing BAT1 and Deleting BAT2," Journal of Agricultural and Food Chemistry, vol. 65, no. 32, pp. 6936-6942, 2017.

[34] J. R. Dickinson, L. E. J. Salgado, and M. J. E. Hewlins, "The catabolism of amino acids to long chain and complex alcohols in Saccharomyces cerevisiae," The Journal of Biological Chemistry, vol. 278, no. 10, pp. 8028-8034, 2003. 
[35] J. Dong, G. Wang, C. Zhang et al., "A two-step integration method for seamless gene deletion in baker's yeast," Analytical Biochemistry, vol. 439, no. 1, pp. 30-36, 2013.

[36] C. Y. Zhang, Y. N. Qi, H. X. Ma et al., "Decreased production of higher alcohols by Saccharomyces cerevisiae, for Chinese rice wine fermentation by deletion of Bat aminotransferases," Journal of Industrial Microbiology Biotechnology, vol. 42, no. 4, pp. 617-625, 2015. 


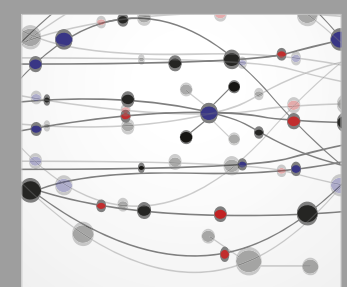

The Scientific World Journal
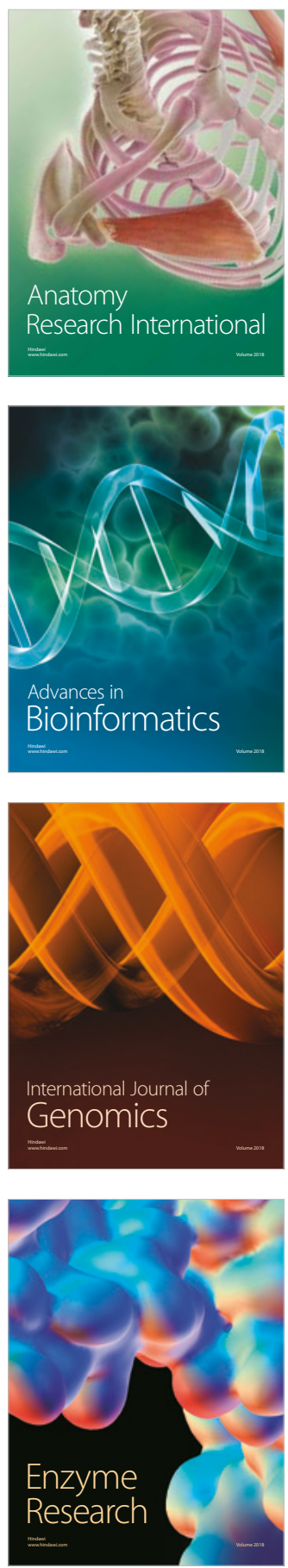
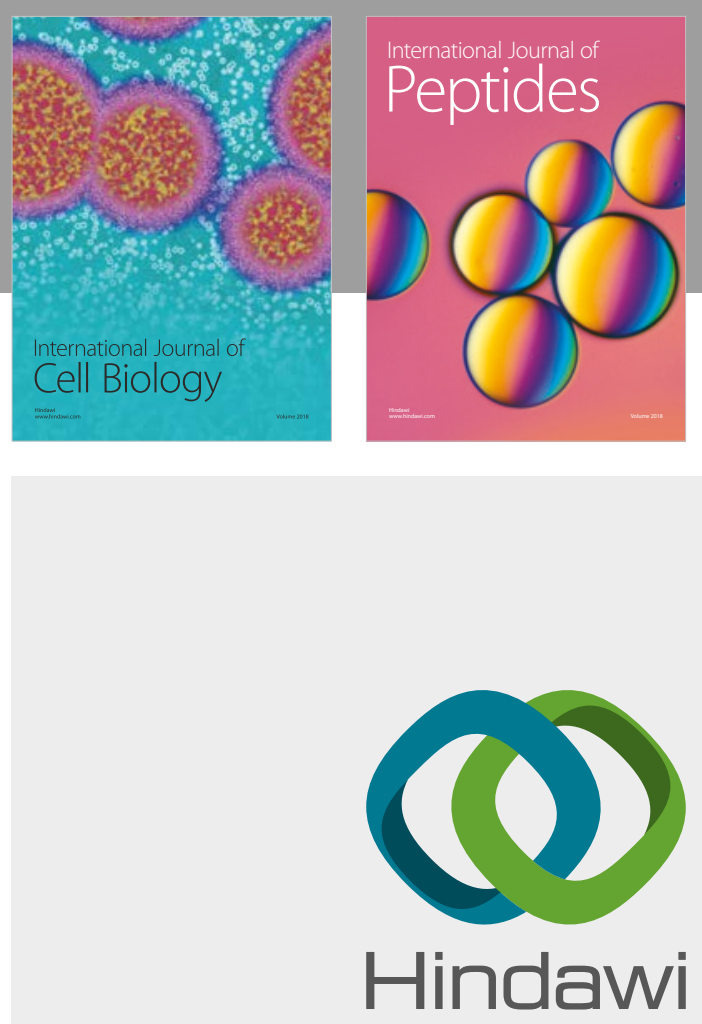

Submit your manuscripts at

www.hindawi.com
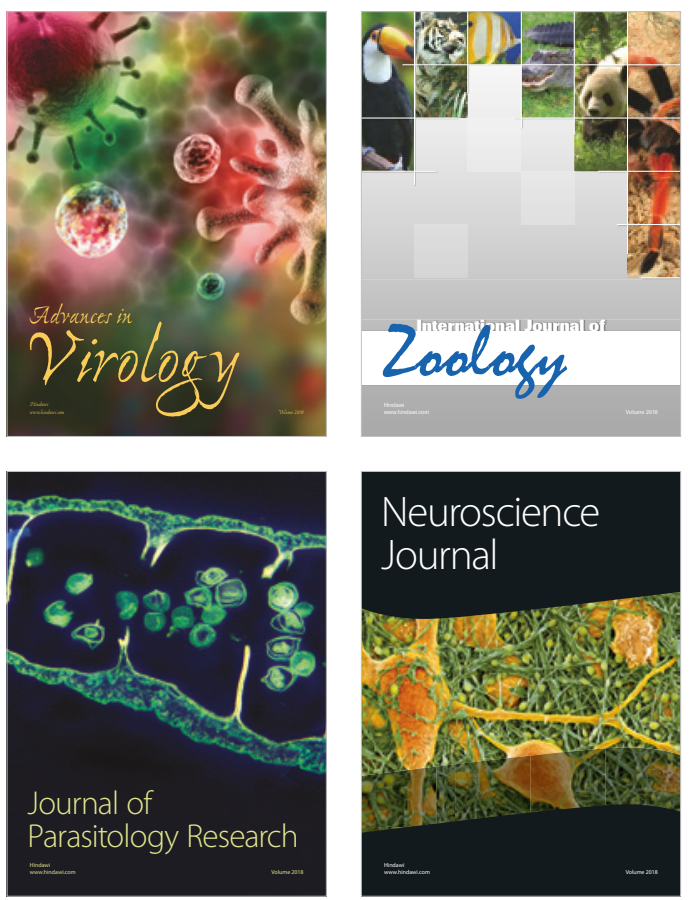
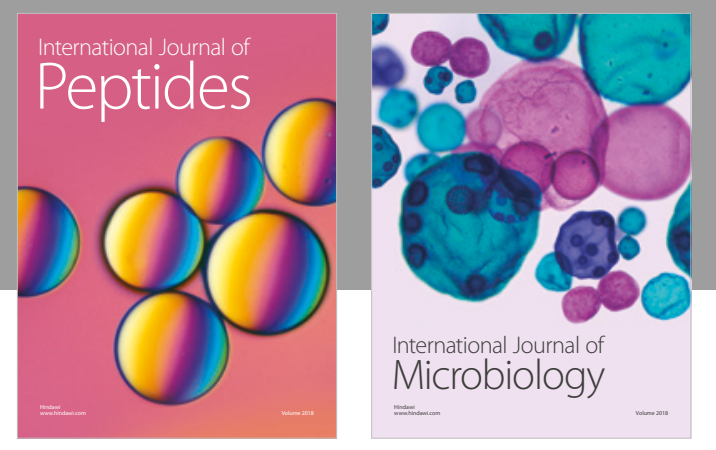

nternational Journal of Microbiology
Journal of
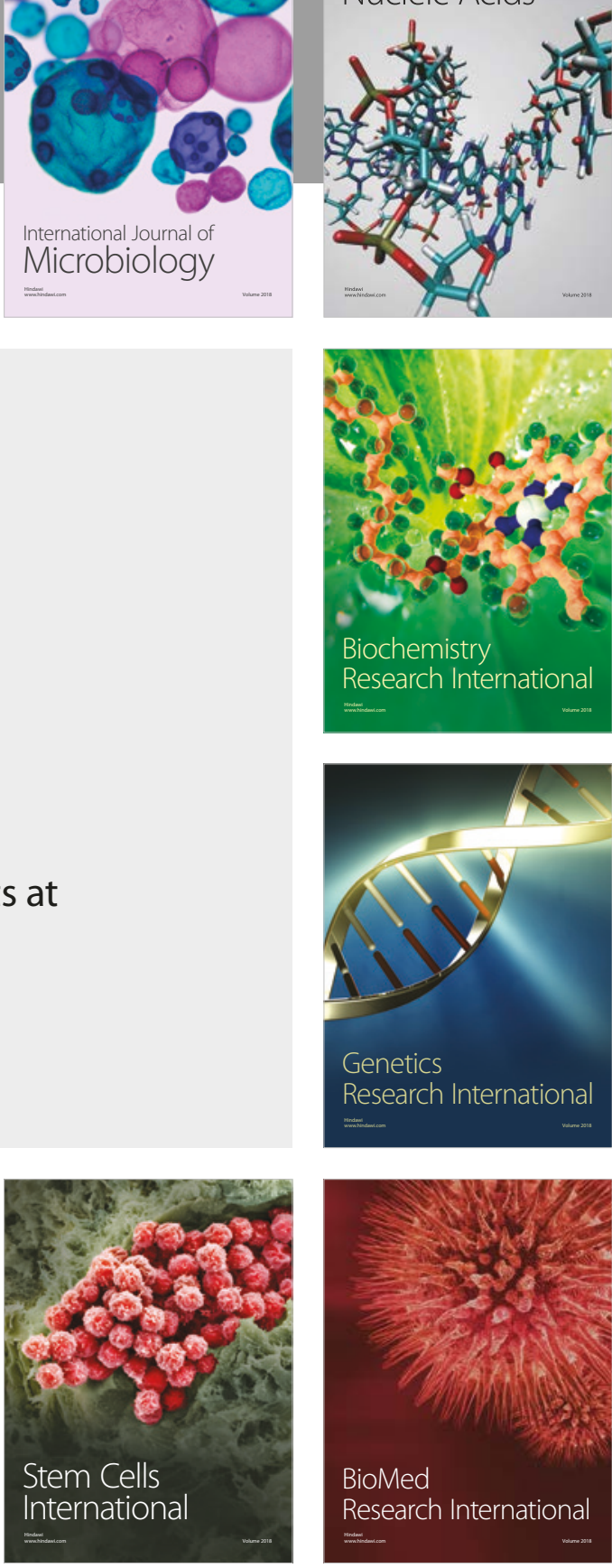
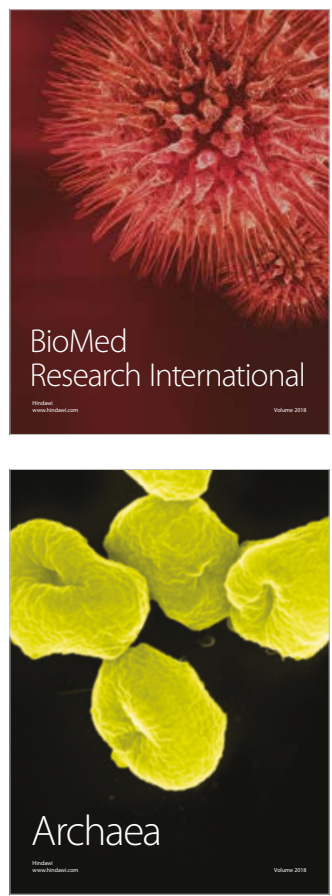